\title{
Spatial and Temporal Variability of Visceral Leishmaniasis in Colombia, 2007 to 2018
}

\author{
Adriana Castillo-Castañeda, ${ }^{1}$ Giovanny Herrera, ${ }^{1}$ Martha S. Ayala, ${ }^{2}$ Patricia Fuya, ${ }^{3}$ and Juan David Ramírez ${ }^{1 *}$ \\ ${ }^{1}$ Centro de Investigaciones en Microbiología y Biotecnología-UR (CIMBIUR), Facultad de Ciencias Naturales, Universidad del Rosario, \\ Bogotá, Colombia; ${ }^{2}$ Grupo de Parasitología, Instituto Nacional de Salud, Bogotá, Colombia; ${ }^{3}$ Grupo de Entomología, Instituto Nacional de Salud, \\ Bogotá, Colombia
}

\begin{abstract}
Visceral leishmaniasis (VL) is a neglected tropical disease associated with poverty and is endemic in 56 countries worldwide. Brazil, Venezuela, and Colombia are the most affected countries in South America. In Colombia, the National Public Health Surveillance System (SIVIGILA) consolidates epidemiological information and monitors all VL cases nationwide. However, to date, no studies have investigated the occurrence of VL in Colombia using metadata analysis. We studied the demographic data, the spatial and temporal distribution of VL cases, and the association with vector distribution of Leishmania species in Colombia from 2007 to 2018. We found 306 VL cases reported to SIVIGILA for this period, with a coverage of 25.5 cases/year, and a mortality of $2.28 \%$ (seven deaths). The highest number of confirmed cases $(N=52)$ occurred in 2007 ; the lowest $(N=9)$ occurred in 2012 . The cases were reported mainly in children $(<7$ years) affiliated with the subsidized health regimen. Regarding the geographic distribution, the cases were reported by 42 municipalities distributed in 10 departments. The occurrence of VL cases toward the northeast of Colombia, and the distribution of vectors, such as Lutzomyia longipalpis and Lu. evansi, may be changing the panorama of VL in the country. We conclude that VL, mainly in recent years, shows a temporal and spatial variability associated with the occurrence of cases in new settings. Our findings increase our understanding and knowledge of this disease, and suggest the need to monitor and prioritize areas with changes in geographic expansion to improve prevention and control actions in the country.
\end{abstract}

\section{INTRODUCTION}

Globally, vector-borne diseases constitute a major public health problem because of their high incidence and complex control-particularly in endemic areas, where transmission rates are high. ${ }^{1,2}$ This group of diseases includes leishmaniasis, which is transmitted primarily by the bite of the female sand fly of the Phlebotominae family that is infected with promastigotes of the protozoan parasite Leishmania. ${ }^{3}$ The disease has three main clinical forms, named according to the anatomic location affected in the host: cutaneous leishmaniasis (CL), mucosal leishmaniasis, and visceral leishmaniasis (VL). ${ }^{4}$ The presentation and evolution of each clinical form has been attributed to multifactorial characteristics of the parasite and the host. ${ }^{5}$

$\mathrm{VL}$ is recognized as the most serious form of leishmaniasis. In VL pathology, the amastigote stage of the parasite invades vital organs, such as the liver and spleen, and tissues such as bone marrow. Physiological and metabolic functions of the body are altered, leading to death if patients do not receive timely treatment. ${ }^{6}$ Historically, the etiology of VL has been attributed mainly to species of the Leishmania donovani complex $x^{3,7}$ and, to a lesser extent, species of the $L$. enrietti complex ${ }^{8}$; however, in recent years, there have been reported cases of VL associated with other species, including L. colombiensis, ${ }^{9}$ L. amazonensis, ${ }^{10,11}$ and $L$. tropica. ${ }^{12}$

According to official reports of the Global Leishmaniasis Program of the WHO for January 2020, 56 countries are endemic for VL, with $90 \%$ of the cases occurring in Brazil, Ethiopia, India, Kenya, Somalia, South Sudan, and Sudan. ${ }^{1}$ Annually, there are an estimated 50,000 to 90,000 new cases worldwide; however, the disease may be underreported by as

\footnotetext{
*Address correspondence to Juan David Ramírez, Centro de Investigaciones en Microbiología y Biotecnología-UR (CIMBIUR), Facultad de Ciencias Naturales, Universidad del Rosario, Bogotá, Colombia. E-mail: juand.ramirez@urosario.edu.co
}

much as $55 \%$ to $75 \% .{ }^{13}$ According to reports by the Drugs for Neglected Diseases initiative, about 20,000 to 30,000 deaths are attributed to VL every year. ${ }^{14}$ In 2018 , the majority of indigenous VL cases in the Americas was reported in Brazil ( $N=$ $3,460)$, Venezuela $(N=43)$, Paraguay $(N=19)$, and Colombia $(N=16) .{ }^{15}$ However, incidence has been greatly affected by climate change, migratory movements, and internal political crises. This last factor leads to health deficits and the disruption of public health programs. ${ }^{16-18}$

In Colombia, the National Public Health Surveillance System (SIVIGILA) was created with Decree 3518 in 2006 to provide information rapidly and systematically on diseases of public health interest, and thus guide policies and programs aimed at the prevention, control, and monitoring According to information provided by the Colombian government, the occurrence of indigenous VL cases has been limited primarily to two geographically defined areas known as the Magdalena River and the Montes de María subregion, San Andrés de Sotavento (Córdoba). ${ }^{19}$ In Magdalena River, there are four VL-endemic departments: Huila, Tolima, Cundinamarca, and Santander. In the Montes de María subregion, the endemic departments are Bolívar and Sucre. In addition, there have been cases reported in the department of Córdoba in the same subregion of the Caribbean coast. However, in recent years, SIVIGILA has recorded indigenous cases occurring in new departments, as well as cases imported from other countries. ${ }^{20-22}$

In endemic municipalities, the public health laboratories perform surveillance and focus studies to understand VL transmission. During entomological studies, occurrences of Lutzomyia longipalpis and $L u$. evansi infected with $L$. infantum have been reported in areas with cases of VL. Similarly, researchers have studied the distribution of vectors involved in the transmission of $L$. infantum, ${ }^{23-25}$ including $L u$. evansi in the northwest of the country and Lu. longipalpis in the Andean region, with a high prevalence in Huila, Tolima, and Cundinamarca. ${ }^{23}$ In addition, analysis of biological samples from 
canines has revealed different rates of infection in four endemic departments: Bolívar, $36 \%{ }^{26}$; Sucre, $33.6 \%{ }^{27}$ to $66.9 \%{ }^{28}$; Huila, $17.2 \%{ }^{29}$; and Tolima, $31.5 \% .{ }^{30}$ Furthermore, a similar panorama of infection rates has been observed in endemic areas of Venezuela, 24.1\% ${ }^{31}$; Spain, > 34\% ${ }^{32}$; Brazil, $45.6 \%{ }^{33}$; and Bangladesh, 35\%. ${ }^{34}$

At the national level, metadata studies have shown changes in the demographic pattern and distribution of the disease and vectors in relation to CL as well as VL. ${ }^{35-37}$ However, despite the importance of this disease and the mandatory reporting of all VL cases in SIVIGILA, the combined geospatial and temporal variation of $\mathrm{VL}$ in Colombia has not yet been documented, and the full extent of the changes in the national distribution of this parasitic disease remains unknown. Therefore, this study aimed to describe the temporal and spatial distribution of VL in Colombia from 2007 to 2018 and to analyze descriptively the occurrence and distribution of the disease. Using publicly available information from official governmental sites and scientific data, we conducted statistical analyses and made biological associations with the vector distributions. Our results provide a scientific basis in relation to spatial and temporal changes and vector distribution for VL, which will help disease monitoring and deployment of public health strategies and programs aimed at the effective and efficient prevention and control of $\mathrm{VL}$ transmission in endemic areas of the country.

\section{METHODS}

Data collection and processing. The information recorded in the SIVIGILA platform are reported by the primary national data-generating units, which are obliged to report events of public health interest in Colombia. These events may be related to infectious diseases (including VL), noncommunicable diseases, or mortality-related events. The primary national data-generating units correspond to institutions providing health services at the municipal level (third sub-national territorial and administrative levels). The registered information was consolidated and checked at the department level (second sub-national territorial and administrative levels) by professionals of the public health surveillance department of INS (National Institute of Health) to verify cases and confirm their status.

We obtained the data available in reports of public health events from 2007 to 2018 and event microdata (for VL) from 2007 to 2017 from the SIVIGILA website (https://www.ins. gov.co/Direcciones/Vigilancia/Paginas/SIVIGILA.aspx). In addition, the 2018 Leishmaniasis Events report by the National Laboratory of Reference-Parasitology Group from the INS was used to corroborate the information. The tables for each year were consolidated with the addition of demographic data from the National Statistics Department (Departamento Administrativo Nacional de Estadística [DANE]) available in the document Estimation and Projection of Total National, Departmental, and Municipal Population by Area 1985-2020 for 2007 to 2017 and Population Projections 2018-2020 for 2018 to take advantage of the data updates by DANE, and thus obtain a more accurate estimate. The data on case occurrences were organized annually and biannually using Microsoft Excel (v. 2018; Microsoft Corp., Redmond, WA) at both the department and municipal levels.
For VL cases where there was no information about the municipality of origin were weighted in the department for the year of occurrence. Thus, the case was added to the municipality that had more cases reported by department during the year of analysis.

Cases of unknown department origin or Venezuelan origin were not used when analyzing incidence. Data on the national distribution of Leishmania vectors (mainly the sand flies associated with species transmitting $\mathrm{VL}$ ) were taken from the entomological surveillance report for leishmaniasis of the $\mathrm{INS}^{38}$ and research articles by Ferro et $\mathrm{al}^{23}$ and Bejarano et al. $^{39}$ The data were consolidated and filtered to construct a map of Colombia showing the geographic distribution of the Leishmania vectors (Lutzomyia spp.) and their relationship to VL cases. The map was made using QGIS software (v. 3.24.1, Washington, DC).

Statistical analysis. Descriptive statistical analysis of the data was performed to determine the demographic characteristics of the population with VL. The variables analyzed were age, gender, department of origin, affiliation to the health system, and number of deaths. The variable "affiliation to the health system" included four categories: contributory regimen (workers and pensioners contributing to the health system for their care and that of their family members), subsidized regimen (unemployed people from socioeconomic strata 1 and 2 who receive many health services free of charge), other (special regimes, such as those for indigenous, military, or state teachers), and none (no affiliation to any health regimen).

To show differences in infection by gender, a normality test was performed for age in both groups (male and female). Because the data were not distributed normally, we proceeded to present the data with median and interquartile range values. Later, a Mann-Whitney $U$ test was performed to evaluate the existence of differences among ages by gender.

These demographic variables were also used to perform a multivariate linear regression to determine whether the cases had an association with the covariates available in the public databases used. Given the small number of cases, we collated all cases in the study period into a single analysis by departments. We calculated standardized incidences based on the total population by department. Standardized incidence ratios (SIRs) were calculated from the total number of cases in Colombia over the study period using empirical Bayesian smoothing as described by Clayton and Kaldor. ${ }^{40}$ We constructed probability maps based on the empirical negative binomial distribution for the data. Last, we calculated measures of spatial autocorrelation in several ways. A global Moran's I randomization test on the SIRs was performed, and spatial weight matrices were based on first-order queen contiguity.

Municipal crude incidence (lo) was calculated by dividing the number of VL cases per year by the population, and the result was recorded per 100,000 inhabitants. The same calculation was made at the department level, and the data were plotted on a heat map using ggplot2 (R package, v. 3.6.1). To display the cases and incidences data in a timeline, the number of cases and lo data were smoothed using Lowess regression. To show the geographic evolution of VL cases during the analyzed period, a map of Colombia was drawn showing the VL biannual incidence rates from 2007 to 2018 by department using QGIS software. 


\section{RESULTS}

Description of sociodemographic data of patients with VL in Colombia. For the years analyzed, 306 laboratoryconfirmed cases of VL in Colombia were reported to SIVIGILA. Four of these cases were associated with a department of unknown origin and one originated abroad (Venezuela), and thus were discarded from the statistical analyses. In general, most VL cases occurred in children; $75 \%$ of the patients were between 0 and 7 years old, with a median of 2 years. The remaining $25 \%$ of patients were between 8 and 78 years old (Table 1). There were no statistically significant differences in cases of VL between the sexes at the national level $\left(X^{2}=\right.$ $0.40199, P=0.5261)$. Regarding social security affiliation, most of the patients were in the subsidized regimen $(73.2 \%)$ or they were not affiliated with any health system regimen (15.6\%), which can be extrapolated to represent conditions of vulnerability associated with poverty because, in the subsidized regimen of the health system in Colombia, people from socioeconomic strata 1 and 2 are affiliated to this one. Similarly, not being affiliated with any health regimen implies greater vulnerability in relation to the difficulty of accessing health services coupled with poverty. For the years analyzed, seven $(2.29 \%)$ cases reported to SIVIGILA were individuals who had died.

Characterization of VL cases and incidence by department. Analysis showed the existence of two geographically defined groups for the presentation of VL in the country-one in the north and the other toward the center of the country-in the departments that converge on the Magdalena River (Figure 1). Each area contains three main departments: the North Zone consists of Bolívar, Sucre, and Córdoba, whereas the Central Zone contains Huila, Tolima, and Cundinamarca. The comparison between observed and expected cases showed SIR values that demonstrated the high level of risk of $V L$ occurrence mainly in the North Zone (Bolívar, Sucre, and Córdoba), where the transmission of the parasite and the presentation of the disease are historically recorded (Figure 1) and the population is lower in comparison with the departments in the Central Zone.

The clear pattern in the geographic distribution of $V L$ in Colombia had an impact on the occurrence and incidence of cases per 100,000 inhabitants at the department and municipal levels. The departments with the greatest occurrence were Bolívar (105 cases), Sucre (76 cases), and Córdoba (70 cases), followed by Huila ( 28 cases) and Tolima (11 cases) (Figure 2A). Since 2016, the number of VL cases in Huila began to exceed those in Sucre and Córdoba. Interestingly, between 2010 and 2012, there was a marked decrease in the number of cases in the three departments that generally have the greatest number of cases per year. In 2012, only nine cases were reported in Colombia, seven in Huila, and the other two in Sucre and Tolima (Supplemental Table 1). We then analyzed annual incidence by department (Figure 2B), and although, until 2015, the department with the greatest number of cases was Bolívar, Sucre had the greatest annual incidence. As of 2016, both the incidence and number of cases reported in Bolivar were the greatest in the entire country. However, Huila has also begun to be an important department for VL in recent years; in 2017, the incidence exceeded that of Sucre and Cordoba. In 2018, the number of cases exceeded those of the two regions.

In congruence with the previous analyses, the histograms of observed cases and their trends showed that, in Colombia, the presentation of $\mathrm{VL}$ is a highly variable phenomenon over time and that it does not follow a certain pattern. It has a tendency to increase or decrease in the number of cases per year (Supplemental Figures 1 and 2). In addition to this finding, it noticed that during the first months of each year, there is a seasonality factor, with an increase in the number of cases reported (Supplemental Figure 2).

Characterization of VL cases and incidence by municipality. When we analyzed the crude incidence of $V L$ at the interdepartment and municipal levels, we observed high data variation and congruence in their distribution (Figure 3A). At a lower level, we found 42 municipalities reporting VL cases in the analyzed period. The municipalities with the greatest historical incidence per year were EI Carmen de Bolívar, Ovejas, and San Andrés de Sotavento (Figure 3B), in the departments of Bolívar, Sucre, and Córdoba, respectively. However, the greatest incidence was reported in Chalán (Sucre), with 34.46 and 34.34 cases/inhabitant in 2010 and 2009 , respectively. In Huila, the annual VL cases were reported by different municipalities, and the number of cases reported was not constant over time. Notably, in the department of La Guajira, all VL cases were limited to the municipality of Hatonuevo (Figure 3b).

TABLE 1

Sociodemographic characteristics of patients with visceral leishmaniasis in Colombia reported to the National Public Health Surveillance System from 2007 to 2018

\begin{tabular}{|c|c|c|c|c|c|c|c|c|c|c|c|}
\hline \multirow[b]{2}{*}{ Variable } & \multicolumn{11}{|c|}{ Location in Columbia } \\
\hline & Bolivar & Córdoba & Sucre & Cesar & Huila & Tolima & Cundinamarca & Santander & Norte de Santander & La Guajira & Total \\
\hline No. of cases & 105 & 70 & 76 & 1 & 28 & 11 & 6 & 1 & 1 & 2 & 301 \\
\hline No. of deaths & 2 & 2 & 1 & 0 & 2 & 0 & 0 & 0 & 1 & 0 & 8 \\
\hline Age, y; median (IQR) & $3(1-7)$ & $2(1-8)$ & $2(1-8)$ & * & $1(1-3)$ & $2(1-2)$ & $26(22.75-77.26)$ & $\dagger$ & * & $\ddagger$ & $2(1-7)$ \\
\hline \multicolumn{12}{|l|}{ Gender } \\
\hline Female & 50 & 31 & 32 & 1 & 19 & 9 & 2 & 0 & 0 & 0 & 144 \\
\hline Male & 55 & 39 & 44 & 0 & 9 & 2 & 2 & 1 & 1 & 2 & 155 \\
\hline \multicolumn{12}{|c|}{ Regimen in the health system } \\
\hline Contributive & 4 & 9 & 1 & 0 & 6 & 2 & 4 & 0 & 0 & 0 & 26 \\
\hline Subsidized & 79 & 52 & 62 & 1 & 21 & 5 & 2 & 1 & 0 & 2 & 225 \\
\hline None & 22 & 8 & 13 & 0 & 0 & 4 & 0 & 0 & 1 & 0 & 48 \\
\hline Other & 0 & 1 & 0 & 0 & 1 & 0 & 0 & 0 & 0 & 0 & 2 \\
\hline
\end{tabular}

IQR = interquartile range.

*Only case $(15 \mathrm{y})$.

$\dagger$ Two cases (15 and $34 \mathrm{y})$.

$\ddagger$ Two cases (1 and $5 \mathrm{y}$ ). 
2007

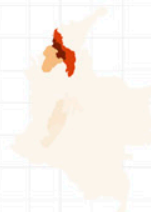

2008

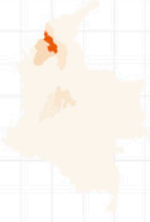

2009

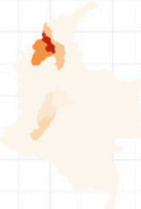

2010<smiles>[Te]=[Te]</smiles>

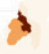
.

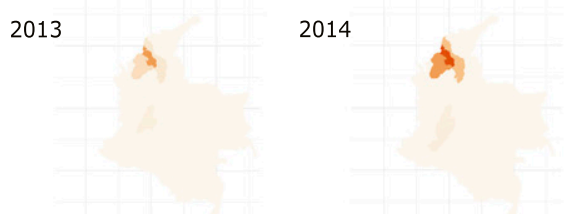

2015



2016

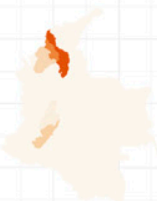

2011

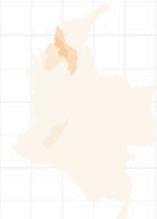

2017

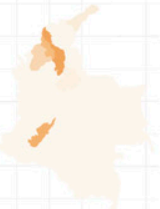

2012

2018

FIGURE 1. Exploratory data analysis of the occurrence and incidence of visceral leishmaniasis cases in Colombia. The political map of Colombia divided into departments the occurrence of observed cases (left), the occurrence of expected cases (middle), and standardized incidence ratio (SIR) (right) per year from 2007 to 2018. This figure appears in color at www.ajtmh.org.

Analysis of the changes in VL distribution demonstrated by biannual incidence. By plotting the biannual lo of VL both temporarily and spatially by department, we see that, initially, from 2007 to 2010, there were two geographically defined areas of VL occurrence (Figures 1 and 4). Historically, the northern departments have been mostly affected; for example, incidences of more than 1.2/100,000 inhabitants have occurred in Sucre, compared with the more stable and lower VL incidence in the entire country $(0.31-0.60 / 100,000$ inhabitants during the years analyzed) (Figure 4). When we compared the distribution and initial incidence of VL of the 2007-08 biennial data with the 2017 to 2018 data, it was seen that, as VL incidence of departments in central Colombia decreased, sporadic instances of new cases began to be reported in the departments of Santander, Cesar, and La Guajira, shifting the VL distribution toward the northwest.

When we calculated measures of spatial autocorrelation, we did not obtain evidence of significant spatial autocorrelation (Moran's I randomization test on the SIRs, $\mathrm{z}=-0.082$, pseudo$P=0.39$ ). We then constructed a probability map based on the empirical negative binomial distribution of the data (Figure 5).
Because we did not have evidence of significant spatial autocorrelation, we chose not to calibrate any models.

Species specificity in the distribution of vectors and VL foci cases. We compared the entomological data registered from various research groups and the data from the Entomology Reference Laboratory of the INS with the national distribution of sandflies in relation to the VL endemic departments (Figure 6). The geographic correlation performed fits a spatial ecological association inference. The distribution of $L u$. evansi was related mainly to the distribution of VL cases in northern Colombia (Bolívar, Sucre, and Córdoba) and in the northeastern departments (Norte de Santander, Cesar, and La Guajira). In these latter departments, VL cases have been reported in the past few years.

In contrast, in Huila, Tolima, and Cundinamarca, Lu. longipalpis was the primary vector distributed in these departments. Lutzomyia longipalpis has also been reported in some foci of the Montes de María subregion, Norte de Santander and La Guajira. Similar concomitance was observed in the distribution of Lu. gomezi (CL Leishmania spp. vector) with VL cases from the Andean area to northern Colombia. Last, $L u$.
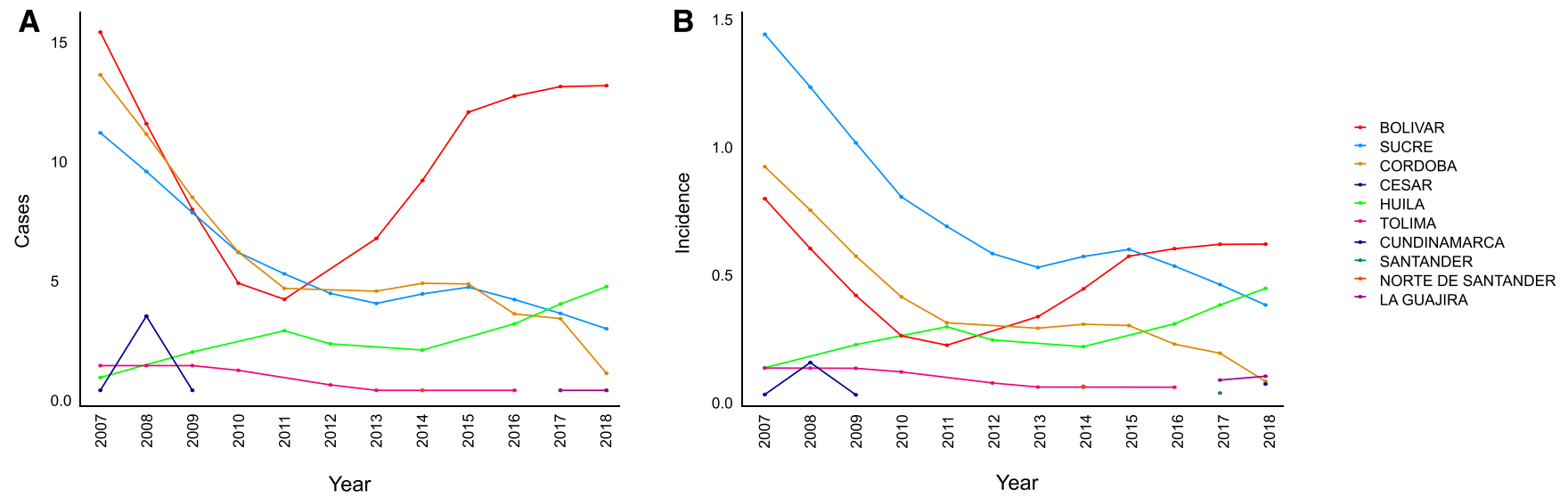

Figure 2. (A) Occurrence and (B) incidence per 100,000 inhabitants of visceral leishmaniasis (VL) at the departmental level. Lowess fit was used to smooth the frequency of $\mathrm{VL}$ (cases, incidence) by department in a time-series graph. The single point represents a department in which a unique case was reported. This figure appears in color at www.ajtmh.org. 
A

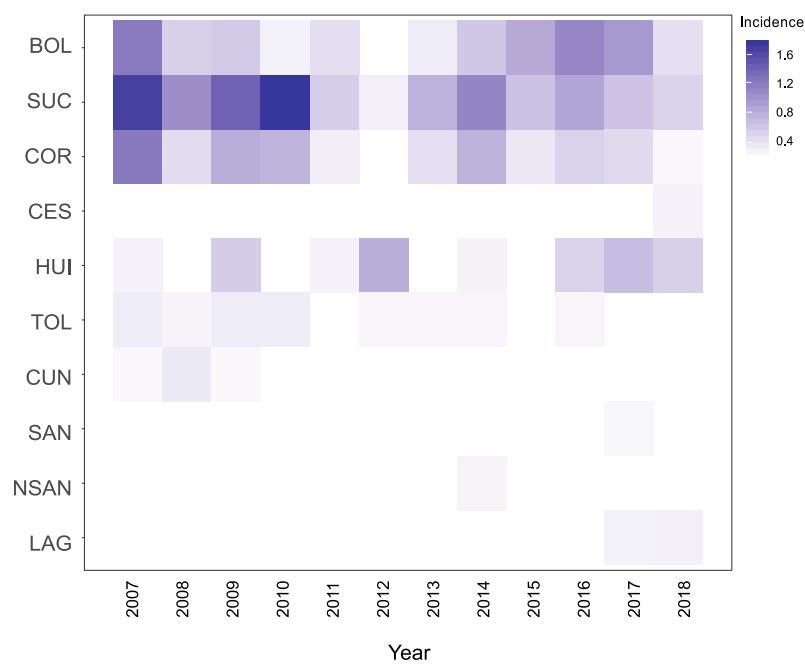

B

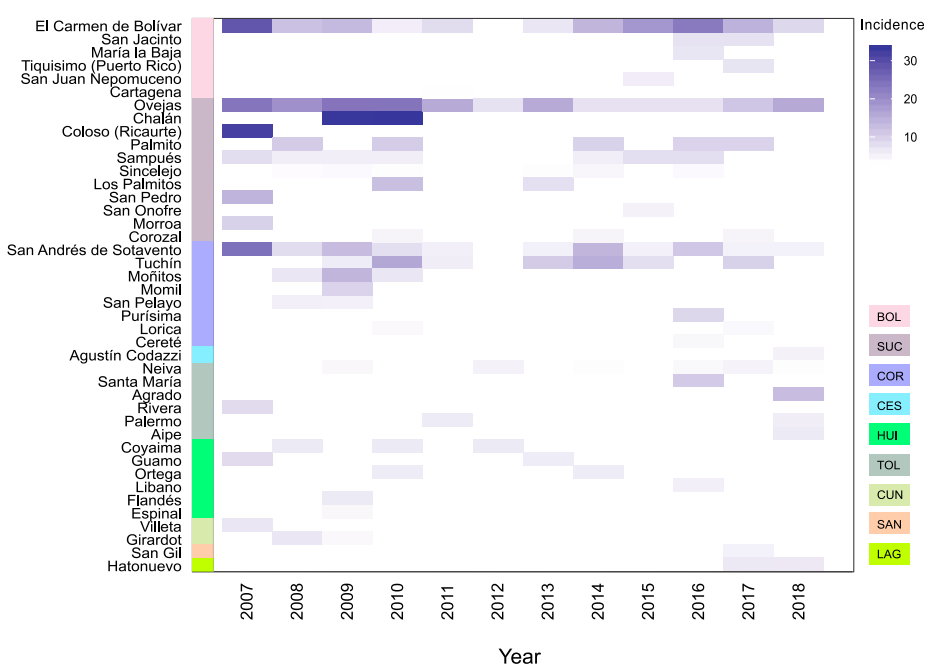

FIGURE 3. Heat map of visceral leishmaniasis incidence variation at the (A) department and (B) municipal levels. Incidence is 100,000 inhabitants/ year. $\mathrm{BOL}=$ Bolívar; $\mathrm{SUC}=$ Sucre; $\mathrm{COR}=$ Córdoba; $\mathrm{CES}=$ Cesar; $\mathrm{HUI}=$ Huila; $\mathrm{TOL}=$ Tolima; $\mathrm{CUN}=\mathrm{Cundinamarca} ; \mathrm{SAN}=\mathrm{Santander} ; \mathrm{NSAN}=\mathrm{Norte}$ de Santander; LAG = La Guajira. This figure appears in color at www.ajtmh.org.

columbiana (CL Leishmania spp. vector) was only found in the Andean area, and the absence of vectors associated with the transmission of VL in other departments bordering Venezuela is evident, such as in Arauca, Vichada, and Guaviare (Figure 6).

\section{DISCUSSION}

VL continues to be a major global public health problem in terms of the number of people at risk, related mortalitymorbidity rates, and the increasing emergence of resistance to commonly used drugs. ${ }^{41-43}$ The occurrence of VL in Colombia shows an expansion in its geographic distribution, probably related to the presence of $L u$. evansi and $L u$. longipalpis on new transmission foci (Figure 6). Likewise, the population most affected by this parasitic disease are the children affiliated with the subsidized regimen of the Colombian health system. The results of our study show that cases of VL have occurred mainly in children in situations of vulnerability associated with poverty (Table 1), considered as one of the greatest risk factors for the development and evolution of the disease. ${ }^{44,45}$ In the case of Colombia, not being affiliated with any health system regimen or being in the subsidized regimen is related to belonging to socioeconomic strata 1 and 2, which implies a greater state of economic vulnerability and difficult access to medical and hospital services. According to official reports, in Colombia, people from these socioeconomic strata have a daily income of less than $\$ 2.50$.

In terms of age, the epidemiological behavior of $V L$ in Colombia is similar to that in Central American countries, ${ }^{15}$ Venezuela, ${ }^{15}$ Alagoas (Brazil), ${ }^{46}$ and western and central China, ${ }^{47}$ where children are the most affected by this disease. In contrast, countries with a high prevalence of the disease, such as Brazil (national data), India, and Nepal, show that the adult population is the most affected by $\mathrm{VL},{ }^{15,48,49}$ with a growing number of HIV-positive patients. ${ }^{50}$ In this sense, the marked difference between the populations affected by VL, according to geographic location of occurrence, may be the result of various factors such as the intraspecific genetic variability and divergence of $L$. infantum in the New World and the interspecies genetic variability against species of L. donovani complex of the Old World, ${ }^{7,51,52}$ in which, for example, $L$. donovani has shown a large number of polymorphisms and high genetic diversity. $7,51,53$ In the human host, susceptibility to VL is associated with some human leukocyte antigen type I and II genes, ${ }^{54-56}$ nutritional factors, and immunization rates, which have been found to have protective effects for other infectious diseases, ${ }^{52}$ and there are associations at the vector level in relation to the behavior and adaptation to the ecological niche of the main vectors for Leishmania. $^{25,57-59}$

However, concurrent with studies carried out by the WHO in Brazil, ${ }^{60}$ the presentation of cases in Colombia was not significantly different between genders. Likewise, this variable in conjunction with the other covariates included in our study did not show a direct association with the occurrence of VL cases in the country. This contrasts with a meta-analysis study by Cloots et al., ${ }^{48}$ who reported males in Bangladesh, India, and Nepal are more prone to developing the disease, and have higher seroprevalence rates and risks for seroconversion. However, population studies in relation to the latter two variables have not been conducted in endemic areas in Colombia.

Regarding geographic distribution, VL was found to affect six main departments, with consistent behavior over time, but variability in the number of cases (Figures 1-4), mainly in the municipalities of El Carmen de Bolívar, Ovejas, San Andrés de Sotavento, and Tuchin (Figure 3B). In the other municipalities, the occurrences were usually not sustained over time. In Colombia, there is a trend of an increase of case notifications of VL during the first quarter of each year (Supplemental Figure 2). This fact is possibly associated with the increase in the vector population and its parasite transmission capacity during the rainy season ${ }^{61}$ of the last quarter of the previous year in the foci (http://www.ideam.gov.co/web/tiempo-y-climate/ precipitation-monthly-per-year) and the average incubation time of Leishmania in the host, which ranges from 2 to 6 months after infection in the case of VL. ${ }^{1}$ 

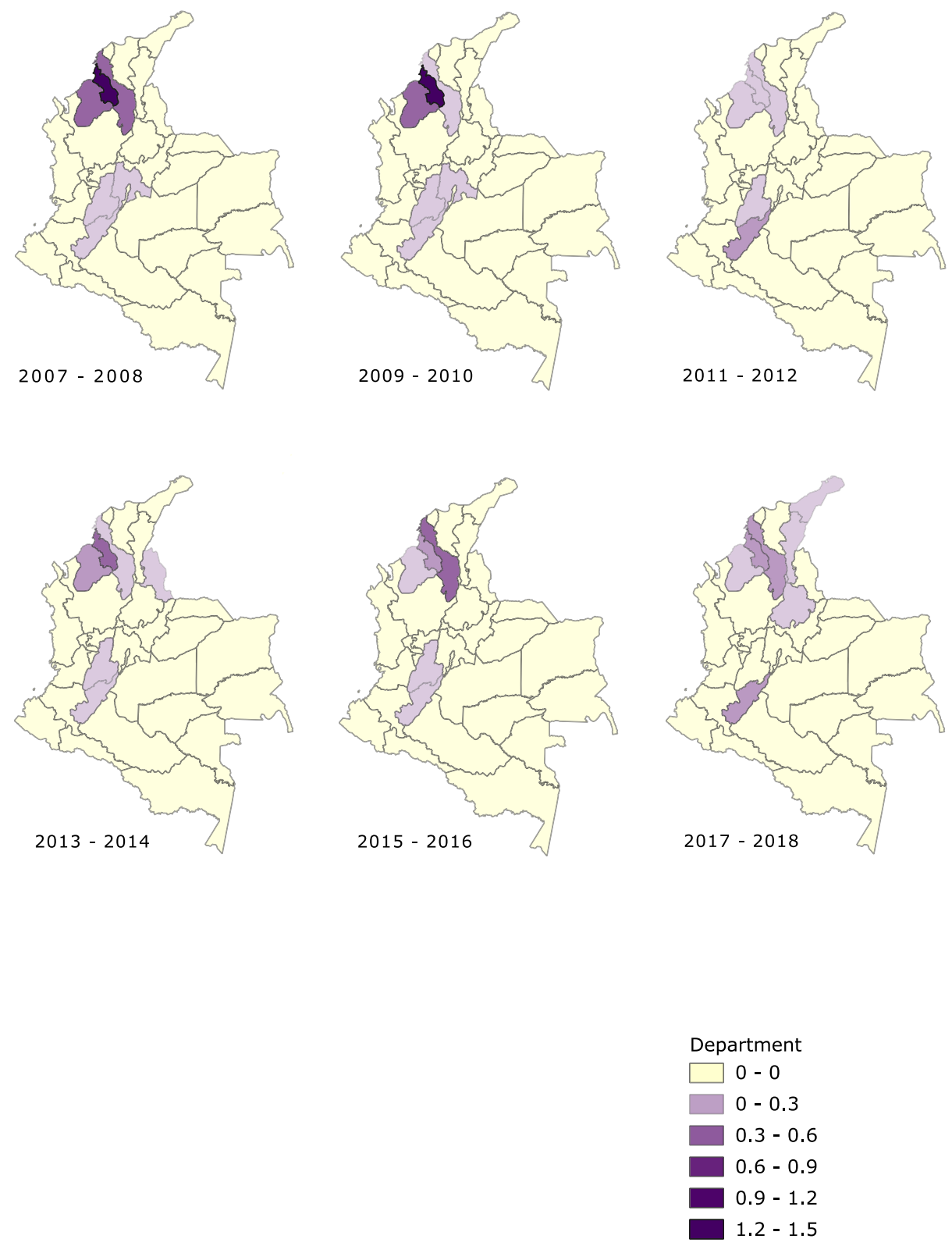

FIGURE 4. Changes in geospatial distribution of visceral leishmaniasis incidence through time by biannual segmentation of department data. Incidence is per 100,000 inhabitants. The map was constructed using QGIS software. This figure appears in color at www.ajtmh.org.

Population abundance and distribution of VL vectors in Latin America, such as L. evansi and L. longipalpis, have been studied in Colombia, Brazil, and Argentina. In general, a direct relationship has been found between increased rainfall and vector abundance, in addition to other environmental factors such as the vegetation richness index. ${ }^{23,62,63} \mathrm{How}-$ ever, regarding the abundance levels of $L$. longipalpis, the climatic conditions can affect each focus of VL in a different way. ${ }^{57,63-66}$ Therefore, keeping the information on population density and vector distribution updated can help entomological surveillance systems improve vector control activities and thus mitigate the incidence of the disease in the country.

As shown in Figure 3B, there was a significant decrease in reported VL cases in 2012 at the national level, with only nine cases occurring in three locations: Neiva $(N=7)$, Ovejas $(N=$
1), and Coyaima $(N=1)$. This interesting change in the pattern of VL occurrence can be related to climate changes that affect the life cycle of the vector. We inferred that the marked decrease in the number of cases could be related to the El Niño-Southern Oscillation phenomenon and hurricane activity in the Atlantic Ocean during $2012 .^{67}$ These meteorological events trigger changes in rainfall, humidity, and continental temperature patterns, ${ }^{68}$ and, when rainfall increases above average, there is less organic matter available for the development of sandflies, ${ }^{69-71}$ leading to a reduction in leishmaniasis transmission rates. ${ }^{72}$ This negative impact on the occurrence of VL has been documented in the Andean region $^{73}$ and Venezuela. ${ }^{74}$ However, da Silva Neto et al. ${ }^{68}$ showed that, in 2012, VL had an increase in incidence (12.37 cases/100,000 inhabitants) in the state of Mato Grosso do Sulen, an area in southern Brazil with particular geographic 


\section{Negative Binomial p-values}

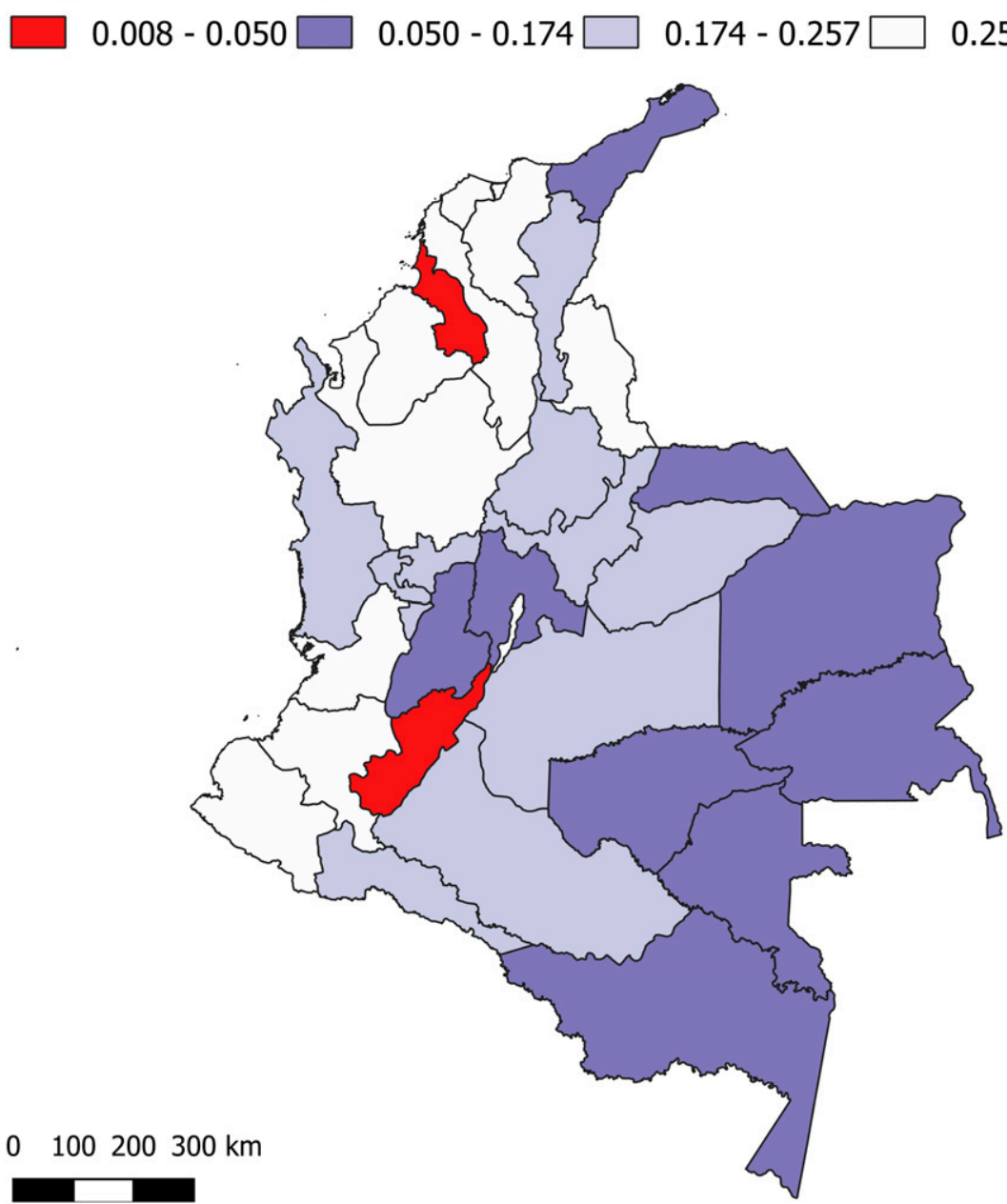

FIGURE 5. Map of empirical negative binomial distribution for the visceral leishmaniasis data in Colombia from 2007 to 2018 . This figure appears in color at www.ajtmh.org.

conditions, and concluded this natural phenomena was related to the greatest VL index recorded in this population.

In general, the areas historically endemic for VL are confined to the North (Montes de María and Córdoba) and Central Zones of the country (Figures 1, 4, and 5). These zones have a wide distribution of Leishmania species-transmitting vectors, such as Lu. longipalpis, Lu. evansi for VL, and Lu. gomezi for CL (Figure 6), and an abundance of reservoir mammals for the parasite,${ }^{37,75}$ which aid the pathogen's epidemiological circuit and, therefore, maintain the transmission rates. Regarding mammalian reservoirs, canines are the main reservoirs for the domestic and peri-domestic transmission of $\mathrm{VL}^{76}$ in Brazil, ${ }^{77,78}$ Spain, ${ }^{79}$ and other endemic countries. Studies have been conducted to measure the impact of canines on the incidence of VL, and the effectiveness of euthanasia and other control strategies to interrupt transmission. ${ }^{80,81}$ However, to carry out effective control of leishmaniasis in endemic areas, it is necessary to resort to One Health strategies, ${ }^{82,83}$ including the concept that the prevention of leishmaniasis requires targeting both canines and the environment in which the insects perpetuate their life cycle. ${ }^{84}$

For VL in Colombia, the epidemiological behavior of the disease in Santander and La Guajira is misleading. By the 19th century, one case of VL had been reported in each of the two departments, in San Vicente de Chucurí-Santander in 1943 (the first case of VL documented in Colombia) ${ }^{85}$ and in Barrancas-La Guajira in $1987,{ }^{86}$ both of which were in infants from rural areas. Curiously, there were reports of cases of CL, but not VL, in various municipalities until VL cases reemerged in 2017 and 2018 (Figure 3B). This panorama, which is similar to that seen in India and Sri Lanka, involving the recent emergence of this clinical form of the disease in new foci, ${ }^{87}$ jeopardizes strategies to control and eliminate leishmaniasis in these territories. New studies are needed specifically in these departments to understand more fully the emerging transmission dynamics of the parasite.

It is important to highlight the presence of different vector species for Leishmania in the new foci mentioned in our study and in other border departments, as parasitological and entomological surveillance should be increased in these areas to control and prevent leishmaniasis outbreaks. ${ }^{3,23}$ In addition, studies on the rates of infection and coinfection in various Phlebotominae species and domestic/peri-domestic/sylvatic reservoirs by the various Leishmania species are necessary to facilitate the prediction of likely VL-causing species in vulnerable populations. This could increase the effectiveness 


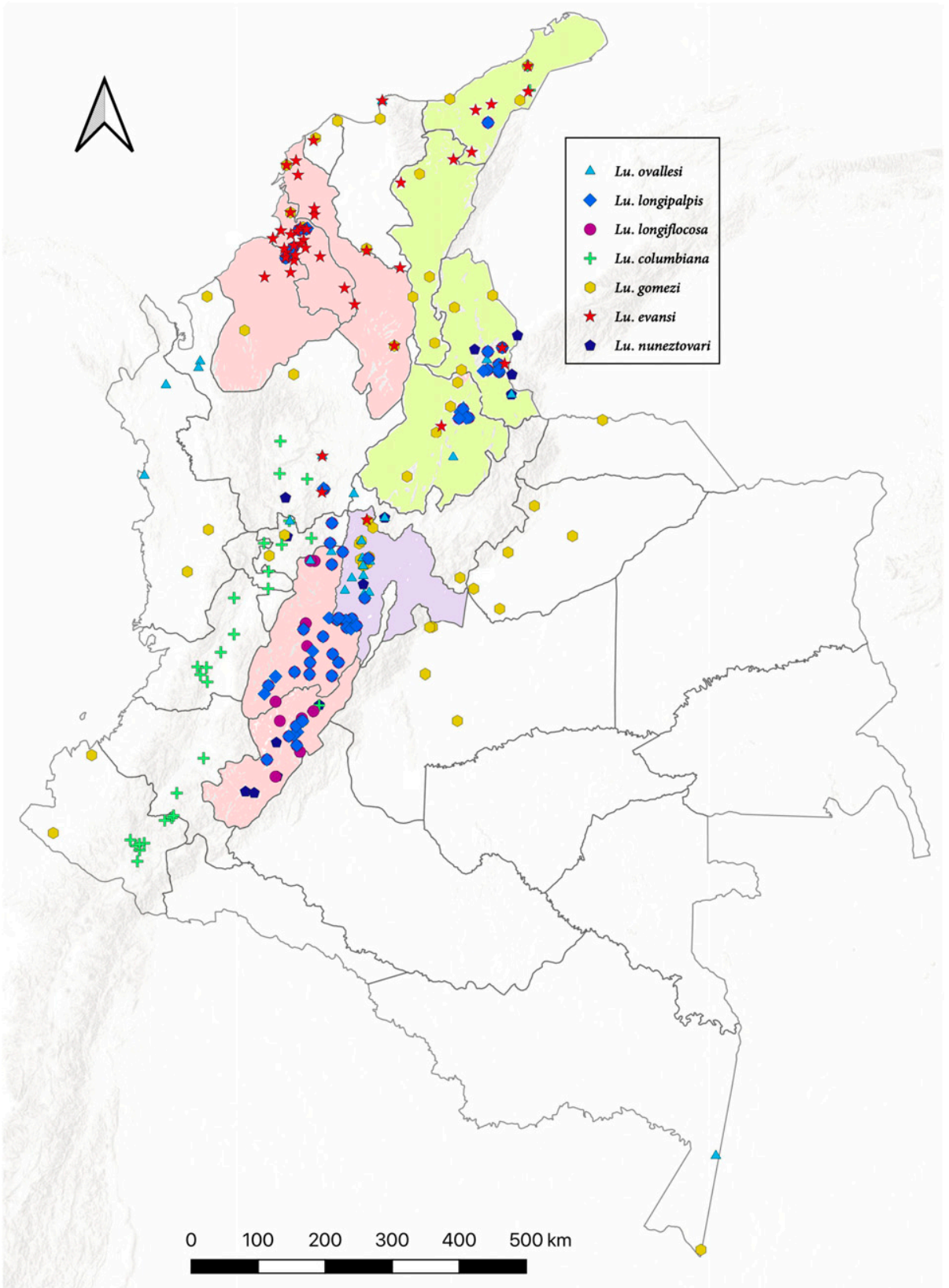

FIGURE 6. Map of visceral leishmaniasis cases and Leishmania vectors implicated in the transmission of the pathogen. The map shows the overlap between vector diversity and total number of departmental cases across the study periods. Pink shading, endemic department with current cases; violet shading, endemic department with cases until 2010; yellow shading, department with new cases. The map was constructed using QGIS software. This figure appears in color at www.ajtmh.org.

of species-specific therapeutic management strategies, which is crucial considering the different intra- and interspecies susceptibility profiles that have been documented worldwide. ${ }^{88-90}$

However, in addition to the presence of vectors and reservoirs, the emergence of $\mathrm{VL}$ in new geographic areas may be associated with environmental factors, such as climate fluctuation ${ }^{91}$; the local intensification of extractive activities $^{92}$; human migration ${ }^{93,94}$; parasite-host interaction factors $^{95}$; host factors, such as nutritional and immunological deficiencies, which are sometimes related to, for example, limited economic resources and limited access to basic sanitation services, education, and self-protection measures $^{44}$; and the intrinsic evolution of parasites, including adaptation to new environments, reduction in life cycle duration, and changes in host immune system evasion. Regarding the immigration of people from Venezuela during the past decade, the cross-border dispersal of Leishmania species has been apparent in both CL and VL cases, as shown in Table 1. In addition to the data used in our study, four cases of VL in the Venezuelan migrant population were reported to SIVIGILA in 2019 and 2020 (http://www.ins. gov.co/buscador-eventos/BoletinEpidemiologico). This phenomenon has been seen for other vector-borne diseases, 
such as Chagas disease, malaria, and arboviral infections, which implies there is a substantial risk of pathogen transmission to the countries bordering Venezuela.

Likewise, considering that although all the official data for VL was used for this 12-year period, the amount of data and the nature of it do not allow statistical analysis of inferences, as is done in countries such as India and Brazil, where the high prevalence of the disease, availability of data, and population studies have allowed generating these types of associations. The low number of nationwide cases reported to SIVIGILA and confirmed by the laboratory may be associated with technical difficulties or medical staff ignorance of the pathology in some areas. Likewise, this possible under-registration of cases and the precarious demographic information available may be a result of the negative impact of the armed conflict in Colombia experienced during this period, which made it difficult for the community to access health services and timely diagnosis and treatment, and affected indirectly the realtime reporting of information in SIVIGILA. Negative effects on war-associated leishmaniasis have been seen in different countries worldwide. ${ }^{47,50,96-98}$ This situation can lead to underreporting of the disease, overestimating the effectiveness of the current $\mathrm{VL}$ promotion and prevention programs, and generating possible biases in our data analyses.

Considering the this scenario along with the high variability of ecological niches, different geographic profiles of $V L$ foci in Colombia, and the various characteristics of the population at risk, we consider that, at this time, to make predictions about the transmission rate and detail the risk factors associated with the acquisition of infection and development of VL could lead to fallacies and erroneous hypotheses at the national and even department levels. Therefore, we suggest that, in addition to using the data on changes in the spatial-temporal distribution of infectious diseases generated by our study, researchers must carry out eco-epidemiological analyses that involve the main actors of VL transmission (parasite/vector/ reservoir/human) and the relationship among with the different determinants and risk factors associated with them. ${ }^{48,99}$ One of the shortcomings of our study is the lack of information related to domestic canines, because they are an important host for the transmission of this zoonotic parasite. ${ }^{100} \mathrm{Un}$ fortunately, there are no population data that show the incidence of this parasitosis in canines in a sustained manner over time, nor with the coverage of all transmission foci in the country, which represents a knowledge gap for the country.

\section{CONCLUSION}

Because ours is the first study to analyze the spatial and temporal evolution of VL from 2007 to 2018 in Colombia, it is highly important that both the scientific community and national regulatory institutions consider the findings of this study regarding the current situation of the disease. Furthermore, population studies and robust predictive models of the disease should be integrated with epidemiological, sociodemographic, zoonotic, and environmental studies to facilitate effective decision making in relation to the surveillance, prevention, and control of these parasites at the national and regional levels, focusing on those populations with a greater risk for infection.

Received January 26, 2021. Accepted for publication March 26, 2021.
Note: Supplemental tables and figure appear at www.ajtmh.org.

Acknowledgments: We thank Dirección de Investigación e Innovación from Universidad del Rosario for providing the English edit of this manuscript. We also thank Ivan Pradilla for his help with the statistical analyses.

Funding support: The publication fee was provided by Dirección de Investigación e Innovación from Universidad del Rosario.

Authors' addresses: Adriana Castillo-Castañeda, Giovanny Herrera, and Juan David Ramírez, Centro de Investigaciones en Microbiología y Biotecnología, UR (CIMBIUR), Facultad de Ciencias Naturales, Universidad del Rosario, Bogotá, Colombia, E-mails: adrianac.castillo @urosario.edu.co, giovannya.herrera@urosario.edu.co, and juand. ramirez@urosario.edu.co. Martha S. Ayala, Grupo de Parasitología, Instituto Nacional de Salud, Bogotá, Colombia, E-mail: mayalas@ ins.gov.co. Patricia Fuya, Grupo de Entomología, Instituto Nacional de Salud, Bogotá, Colombia, E-mail: pfuya@ins.gov.co.

\section{REFERENCES}

1. PAHO W, 2019. Manual de Procedimientos para Vigilancia y Control de las Leishmaniasis en las Américas. Washington, DC: Panamerican Health Organization (PAHO).

2. World Health Organization, 2015. Abordar las Enfermedades Tropicales Desatendidas con el Enfoque de los Derechos Humanos. Geneva, Switzerland: WHO.

3. Akhoundi M, Kuhls K, Cannet A, Votýpka J, Marty P, Delaunay P, Sereno D, 2016. A historical overview of the classification, evolution, and dispersion of Leishmania parasites and sandflies. PLoS Negl Trop Dis 10: e0004349.

4. Alemayehu B, Alemayehu M, 2017. Leishmaniasis: a review on parasite, vector and reservoir host. Health Sci J 11. Available at: https://www.hsj.gr/medicine/leishmaniasis-a-review-onparasite-vector-and-reservoir-host.php?aid=20131.

5. Akuffo H, Costa C, van Griensven J, Burza S, Moreno J, Herrero $M, 2018$. New insights into leishmaniasis in the immunosuppressed. PLoS Negl Trop Dis 12: e0006375.

6. McCall L-I, Zhang W-W, Matlashewski G, 2013. Determinants for the development of visceral leishmaniasis disease. PLOS Pathog 9: e1003053.

7. Franssen SU et al., 2020. Global genome diversity of the Leishmania donovani complex. eLife 9: e51243.

8. Paranaiba LF, Pinheiro LJ, Torrecilhas AC, Macedo DH, Menezes-Neto A, Tafuri WL, Soares RP, 2017. Leishmania enriettii (Muniz \& Medina, 1948): a highly diverse parasite is here to stay. PLoS Pathog 13: e1006303.

9. Rodriguez-Bonfante C, Bonfante-Garrido R, Grimaldi G, Momen H, Cupolillo E, 2003. Genotypically distinct Leishmania colombiensis isolates from Venezuela cause both cutaneous and visceral leishmaniasis in humans. Infect Genet Evol 3: 119-124.

10. Aleixo JA, Nascimento ET, Monteiro GR, Fernandes MZ, Ramos AMO, Wilson ME, Pearson RD, Jeronimo SMB, 2006. Atypical American visceral leishmaniasis caused by disseminated Leishmania amazonensis infection presenting with hepatitis and adenopathy. Trans $R$ Soc Trop Med Hyg 100: 79-82.

11. Carvalho EM, Momem H, Grimaldi G, Barral-Netto M, Badaró R, Barral A, 1986. Isolation of Leishmania mexicana amazonensis from the bone marrow in a case of American visceral leishmaniasis. Am J Trop Med Hyg 35: 732-734.

12. Fakhar M, Pouladfar GR, Alborzi A, Kadivar MR, Hatam GR, Motazedian MH, 2008. Isolation of Leishmania tropica from a patient with visceral leishmaniasis and disseminated cutaneous leishmaniasis, southern Iran. Am J Trop Med Hyg 79: 435-437.

13. World Health Organization, 2020. Leishmaniasis: Newsroom. Geneva, Switzerland: WHO. Available at: https://www.who.int/ neglected_diseases/resources/leishmaniasis/en/.

14. Drugs for Neglected Diseases Initiative, 2020. Visceral Leishmaniasis Disease Background. Available at: https://dndi.org/ diseases/visceral-leishmaniasis/.

15. Panamerican Health Organization, 2019. Epidemiological Report of the Americas: Leishmaniases. Washington, DC: Pan 
American Health Organization. Available at: https://iris.paho. org/handle/10665.2/50505.

16. Afonso MM dos S, Chaves SA de M, Magalhães M de AFM, Gracie R, Azevedo C, de Carvalho BM, Rangel EF, 2017. Ecoepidemiology of American visceral leishmaniasis in Tocantins State, Brazil: factors associated with the occurrence and spreading of the vector Lutzomyia (Lutzomyia) longipalpis (Lutz \& Neiva, 1912) (Diptera: Psychodidae: Phlebotominae). Claborn D, ed. The Epidemiology and Ecology of Leishmaniasis. InTech. Available at: https://www.intechopen.com/books/ the-epidemiology-and-ecology-of-leishmaniasis/ecoepidemiologyof-american-visceral-leishmaniasis-in-tocantins-state-brazilfactors-associated-with.

17. Norman FF, Comeche B, Chamorro S, López-Vélez R, 2020. Overcoming challenges in the diagnosis and treatment of parasitic infectious diseases in migrants. Expert Rev Anti Infect Ther 18: 127-143.

18. Valero NNH, Uriarte M, 2020. Environmental and socioeconomic risk factors associated with visceral and cutaneous leishmaniasis: a systematic review. Parasitol Res 119: 365-384.

19. Palau MT et al., 1990. Distribution and etiology of leishmaniasis in Colombia. Am J Trop Med Hyg 42: 206-214.

20. INS, 2018. Informe de evento: Leishmaniasis 2017. Bogota, Columbia: Instituto Nacional de Salud.

21. INS, 2017. Informe de evento: Leishmaniasis 2016. Bogota, Columbia: Instituto Nacional de Salud.

22. Zambrano P, Ayala MS, Fuya P, Barraza O, Rodríguez Toro G, 2016. Cartagena: new urban focus of visceral leishmaniasis in Colombia. Scielo 7: 83-91.

23. Ferro C, López M, Fuya P, Lugo L, Cordovez JM, González C, 2015. Spatial distribution of sand fly vectors and ecoepidemiology of cutaneous leishmaniasis transmission in Colombia. PLoS One 10: e0139391.

24. González C et al., 2018. Diversity patterns, Leishmania DNA detection, and bloodmeal identification of Phlebotominae sand flies in villages in northern Colombia. PLoS One 13: e0190686.

25. Paternina LE, Verbel-Vergara D, Romero-Ricardo L, Pérez-Doria A, Paternina-Gómez M, Martínez L, Bejarano EE, 2016. Evidence for anthropophily in five species of phlebotomine sand flies (Diptera: Psychodidae) from northern Colombia, revealed by molecular identification of bloodmeals. Acta Trop 153: 86-92.

26. Cortés LA, 2012. Foco de leishmaniasis en El Hobo, municipio de El Carmen de Bolívar, Bolívar, Colombia. Biomedica 26: 236.

27. Paternina-Gómez M, Díaz-Olmos Y, Paternina LE, Bejarano EE, 2013. Alta prevalencia de infección por Leishmania (Kinetoplastidae: Trypanosomatidae) en caninos del norte de Colombia. Biomedica 33. Available at: https://revistabiomedica.org/ index.php/biomedica/article/view/780.

28. Paternina Tuirán LE, Díaz-Olmos YA, Paternina-Gómez $M$, Carrillo-Bonilla LM, Vélez ID, Bejarano Martínez EE, 2015. Detección de anticuerpos anti-Leishmania (Trypanosomatidae) en poblaciones caninas del Departamento de Sucre, Colombia. Acta Biol Colomb 21. Available at: https://www.redalyc.org/ articulo.oa? id=319043374018.

29. Fernández Manrique J, C T, Bello F, Escovar J, Lozano C, Ayala M, Nicholls R, Vargas J, Moncada L, A A, López M, 2002. Prevalence of canine visceral leishmaniasis in municipalities of Huila, Colombia. Rev Salud Publica (Bogota) 4: 278-285. Available at: http://www.scielo.org.co/scielo.php?script=sci_ arttext\&pid=S0124-00642002000300005.

30. Romero MH, López MC, Sanchez JA, 2009. Búsqueda activa de casos de leishmaniasis visceral zoonótica en población infantil indígena y canina colombiana. Rev Salud Publica (Bogota) 11: 944-951.

31. Cannova DC, Aguilar CM, Guevara H, Delgado O, Feliciangeli MD, 2017. Visceral leishmaniasis in low-income urban areas of Carabobo State, Venezuela: I. Human and canine prevalence, risk of infection. Bol Malariol Salud Ambient 57: 58-68.

32. Dujardin J-C, Campino L, Cañavate C, Dedet J-P, Gradoni L, Soteriadou K, Mazeris A, Ozbel Y, Boelaert M, 2008. Spread of vector-borne diseases and neglect of leishmaniasis, Europe. Emerg Infect Dis 14: 1013-1018.

33. Lopes EG et al., 2017. Serological and molecular diagnostic tests for canine visceral leishmaniasis in Brazilian endemic area: one out of five seronegative dogs are infected. Epidemiol Infect 145: 2436-2444.

34. Islam A, Rahman M, Islam S, Debnath $P$, Alam M, Hassan M, 2017. Sero-prevalence of visceral leishmaniasis (VL) among dogs in VL endemic areas of Mymensingh District, Bangladesh. $J$ Adv Vet Anim Res 4: 241.

35. Herrera G, Teherán A, Pradilla I, Vera M, Ramírez JD, 2018. Geospatial-temporal distribution of tegumentary leishmaniasis in Colombia (2007-2016). PLoS Negl Trop Dis 12: e0006419.

36. Ovalle-Bracho C, Londoño-Barbosa D, Salgado-Almario J, González C, 2019. Evaluating the spatial distribution of Leishmania parasites in Colombia from clinical samples and human isolates (1999 to 2016). PLoS One 14: e0214124.

37. Ramírez JD, Hernández C, León CM, Ayala MS, Flórez C, González C, 2016. Taxonomy, diversity, temporal and geographical distribution of cutaneous leishmaniasis in Colombia: a retrospective study. Sci Rep 6. Available at: https://www.nature. com/articles/srep28266.

38. INS, 2018. Informe de Vigilancia Entomológica de Leishmaniasis, Colombia 2018. Bogota, Colombia: Instituto Nacional de Salud.

39. Bejarano EE, Sierra D, Vélez ID, 2003. Novedades en la distribución geográfica del grupo verrucarum (Diptera: Psychodidae) en Colombia. Biomedica 23: 341.

40. Clayton D, Kaldor J, 1987. Empirical Bayes estimates of agestandardized relative risks for use in disease mapping. Biometrics 43: 671-681.

41. Cohen BE, 2016. The role of signaling via aqueous pore formation in resistance responses to amphotericin B. Antimicrob Agents Chemother 60: 5122-5129.

42. Dumetz F, Cuypers B, Imamura H, Zander D, D'Haenens E, Maes I, Domagalska MA, Clos J, Dujardin J-C, De Muylder G, 2018. Molecular preadaptation to antimony resistance in Leishmania donovani on the Indian subcontinent. MSphere 3. Available at: https://pubmed.ncbi.nlm.nih.gov/29669889/.

43. Frézard F, Monte-Neto R, Reis PG, 2014. Antimony transport mechanisms in resistant Leishmania parasites. Biophys Rev 6: 119-132.

44. Alvar J, Yactayo S, Bern C, 2006. Leishmaniasis and poverty. Trends Parasitol 22: 552-557.

45. Hotez P, Ottesen E, Fenwick A, Molyneux D, 2006. The neglected tropical diseases: the ancient afflictions of stigma and poverty and the prospects for their control and elimination. Pollard AJ, Finn A, eds. Hot Topics in Infection and Immunity in Children III. Springer, 23-33. Available at: https://digitalcommons. library.tmc.edu/childrenatrisk/vol4/iss2/10/.

46. Braz BM de A, Silva RBS, Lins SC, Silva DRX, Ramalho WM, de Melo MA, 2021. Demographic and spatial study of visceral leishmaniasis in the state of Alagoas, Brazil, during 2007-2018. Rev Soc Bras Med Trop 54: e06102020. Available at: https://www. scielo.br/scielo.php?pid=S0037-86822021000100310\&script= sci_arttext.

47. Jiang $D$ et al., 2021. Spatiotemporal patterns and spatial risk factors for visceral leishmaniasis from 2007 to 2017 in western and central China: a modelling analysis. Sci Total Environ 764: 144275.

48. Cloots $\mathrm{K}$ et al., 2020. Male predominance in reported visceral leishmaniasis cases: nature or nurture? A comparison of population-based with health facility-reported data. PLoS Negl Trop Dis 14: e0007995.

49. Jervis S et al., 2017. Variations in visceral leishmaniasis burden, mortality and the pathway to care within Bihar, India. Parasit Vectors 10. Available at: https://www.ncbi.nlm.nih.gov/pmc/ articles/PMC5719561/.

50. World Health Organization, 2020. Global Leishmaniasis Surveillance, 2017-2018, and First Report on 5 Additional Indicators. Geneva, Switzerland: WHO.

51. Lypaczewski P, Hoshizaki J, Zhang W-W, McCall L-I, TorciviaRodriguez J, Simonyan V, Kaur A, Dewar K, Matlashewski G, 2018. A complete Leishmania donovani reference genome identifies novel genetic variations associated with virulence. Sci Rep 8: 16549.

52. Boité MC, Späth GF, Bussotti G, Porrozzi R, Morgado FN, Llewellyn M, Schwabl P, Cupolillo E, 2019. Trans-Atlantic spillover: deconstructing the ecological adaptation of Leishmania infantum in the Americas. Genes (Basel) 11: 4. 
53. Downing T et al., 2011. Whole genome sequencing of multiple Leishmania donovani clinical isolates provides insights into population structure and mechanisms of drug resistance. Genome Res 21: 2143-2156.

54. Samaranayake N, Fernando SD, Neththikumara NF, Rodrigo C, Karunaweera ND, Dissanayake VHW, 2016. Association of HLA class I and II genes with cutaneous leishmaniasis: a case control study from Sri Lanka and a systematic review. BMC Infect Dis 16: 292.

55. Singh B, Fakiola M, Sudarshan M, Oommen J, Singh SS, Sundar S, Blackwell JM, 2019. HLA-DR class II expression on myeloid and lymphoid cells in relation to HLA-DRB1 as a genetic risk factor for visceral leishmaniasis. Immunology 156: 174-186.

56. Singh T, Fakiola M, Oommen J, Singh AP, Singh AK, Smith N, Chakravarty J, Sundar S, Blackwell JM, 2018. Epitope-binding characteristics for risk versus protective DRB1 alleles for visceral leishmaniasis. J Immunol 200: 2727-2737.

57. de Santana Martins Rodgers M, Bavia ME, Fonseca EOL, Cova BO, Silva MMN, Carneiro DDMT, Cardim LL, Malone JB, 2019. Ecological niche models for sand fly species and predicted distribution of Lutzomyia longipalpis (Diptera: Psychodidae) and visceral leishmaniasis in Bahia State, Brazil. Environ Monit Assess 191: 331.

58. Hoyos-López R, Bolaños R, Contreras-Gutierrez M, CarreroSarmiento D, 2016. Phlebotomine sandflies (Diptera: Psychodidae) in a sub-Andean forest from the Norte de Santander, Colombia. J Vector Borne Dis 53: 70-76.

59. Bates PA et al., 2015. Recent advances in phlebotomine sand fly research related to leishmaniasis control. Parasit Vectors 8: 131.

60. Oliveira-Sena IV, Werneck GL, 2019. Risk factors for in-hospital mortality from visceral leishmaniasis: a case-control study. $J$ Infect Public Health S1876034119303181. Available at: https://pubmed.ncbi.nlm.nih.gov/31718991/.

61. Mota TF et al., 2019. Natural infection by Leishmania infantum in the Lutzomyia longipalpis population of an endemic coastal area to visceral leishmaniasis in Brazil is not associated with bioclimatic factors. PLoS Negl Trop Dis 13: e0007626.

62. Estrada LG, Ortega E, Vivero RJ, Bejarano EE, Cadena H, 2020. Development of Lutzomyia evansi immature stages in peridomiciliary environment in a leishmaniasis urban focus in the Colombian Caribbean. Acta Trop 208: 105523.

63. Salomon OD 2020. Lutzomyia longipalpis: gone with the wind and other variables. Neotrop Entomol. Available at: https:// www.scielo.br/scielo.php?script=sci_arttext\&pid=S007402762015000700831.

64. Gómez-Bravo A, German A, Abril M, Scavuzzo M, Salomón OD, 2017. Spatial population dynamics and temporal analysis of the distribution of Lutzomyia longipalpis (Lutz \& Neiva, 1912) (Diptera: Psychodidae: Phlebotominae) in the city of Clorinda, Formosa, Argentina. Parasit Vectors 10: 352.

65. Berrozpe PE, Lamattina D, Santini MS, Araujo AV, Torrusio SE, Salomón OD, 2019. Spatiotemporal dynamics of Lutzomyia longipalpis and macro-habitat characterization using satellite images in a leishmaniasis-endemic city in Argentina. Med Vet Entomol 33: 89-98.

66. Ribeiro da Silva RC, Guimarães e Silva AS, da Silva Sousa SS, Bezerra JMT, Macário Rebêlo JM, Pinheiro VCS, 2019. Occurrence of Phlebotominae (Diptera: Psychodidae) in urban leishmaniasis transmission foci in north-eastern Brazil. J Med Entomol 56: 247-253.

67. Meyer RJ, Baker J, Broad K, Czajkowski J, Orlove B, 2014. The dynamics of hurricane risk perception: real-time evidence from the 2012 Atlantic hurricane season. Bull Am Meteorol Soc 95: 1389-1404.

68. da Silva Neto AB, de Oliveira EF, Encina CCC, de Figueiredo HR, Paranhos Filho AC, de Oliveira AG, 2020. Effects of El NiñoSouthern Oscillation on human visceral leishmaniasis in the Brazilian State of Mato Grosso do Sul. Mem Inst Oswaldo Cruz 115: e190298.

69. Carme B et al., 2013. Climate and leishmaniasis in French Guiana. Am J Trop Med Hyg 89: 564-569.

70. Chowell G, Mizumoto K, Banda JM, Poccia S, Perrings C, 2019. Assessing the potential impact of vector-borne disease transmission following heavy rainfall events: a mathematical framework. Phil Trans R Soc Lond B Biol Sci 374: 20180272.

71. Naqvi Z, 2009. Using Remote Sensing to Assess Potential Impacts of Hurricanes on Mosquito Habitat Formation: Investigating the Mechanisms for Interrelationship between Climate and the Incidence of Vector-Borne Diseases. Available at: https://baylor-ir.tdl.org/handle/2104/5530.

72. Watson JT, Gayer M, Connolly MA, 2007. Epidemics after natural disasters. Emerg Infect Dis 13: 1-5.

73. Pérez-Flórez M, Ocampo CB, Valderrama-Ardila C, Alexander N, 2016. Spatial modeling of cutaneous leishmaniasis in the Andean region of Colombia. Mem Inst Oswaldo Cruz 111: 433-442.

74. Cabaniel G, Rada L, Blanco J, Rodriguez-Morales A, Escalera Antezana JP, 2005. Impacto de los eventos de El Niño Southern Oscillation (ENSO) sobre la leishmaniosis cutánea en Sucre, Venezuela, a través del uso de información satelital, 1994-2003. Rev Peru Med Exp Salud Publica 22: 32-37.

75. Alexander B, Lozano C, Barker DC, McCann SHE, Adler GH, 1998. Detection of Leishmania (Viannia) braziliensis complex in wild mammals from Colombian coffee plantations by PCR and DNA hybridization. Acta Trop 69: 41-50.

76. Dantas-Torres F, Solano-Gallego L, Baneth G, Ribeiro VM, de Paiva-Cavalcanti M, Otranto D, 2012. Canine leishmaniosis in the Old and New Worlds: unveiled similarities and differences. Trends Parasitol 28: 531-538.

77. Gomez SA, Chapman LAC, Dilger E, Courtenay O, Picado A, 2018. Estimating the efficacy of community-wide use of systemic insecticides in dogs to control zoonotic visceral leishmaniasis: a modelling study in a Brazilian scenario. PLoS Negl Trop Dis 12: e0006797.

78. Sevá AP, Ovallos FG, Amaku M, Carrillo E, Moreno J, Galati EAB, Lopes EG, Soares RM, Ferreira F, 2016. Canine-based strategies for prevention and control of visceral leishmaniasis in Brazil. PLoS One 11: e0160058.

79. Le Rutte EA, van Straten R, Overgaauw PAM, 2018. Awareness and control of canine leishmaniosis: a survey among Spanish and French veterinarians. Vet Parasitol 253: 87-93.

80. Lopes EGP, Oviedo-Pastrana ME, Borges LFNM, Freitas ACP, Dias ES, Silva SR, Haddad JPA, França-Silva JC, Soares DFM, 2016. Transmission of visceral leishmaniasis in dogs in a risk area of the metropolitan region of Belo Horizonte, Minas Gerais, Brazil. Arq Bras Med Vet Zootec 68: 1403-1412.

81. Dantas-Torres F, Miró G, Bowman DD, Gradoni L, Otranto D, 2019. Culling dogs for zoonotic visceral leishmaniasis control: the wind of change. Trends Parasitol 35: 97-101.

82. Dantas-Torres F et al., 2019. Canine leishmaniasis control in the context of One Health. Emerg Infect Dis 25: 1-4.

83. Vilas VJDR, Maia-Elkhoury ANS, Yadon ZE, Cosivi O, SanchezVazquez MJ, 2014. Visceral leishmaniasis: a One Health approach. Vet Rec 175: 42-44.

84. Otranto D, Dantas-Torres F, 2013. The prevention of canine leishmaniasis and its impact on public health. Trends Parasitol 29: 339-345.

85. Gast A, Renginfo S, 1944. Leishmaniosis visceral: estudio epidemiológico del primer caso diagnosticado en Colombia. Anales Soc Biol 1: 5-12.

86. Morales A, Ferro C, Isaza de Rodríguez C, Cura E, 1987. Encuesta sobre artropodos de interés médico en La Guajira, Colombia, Suramérica. Biomedica 7: 89.

87. Sandhya R, Rakesh PS, Dev S, 2019. Emergence of visceral leishmaniasis in Kollam District, Kerala, southern India. Int $J$ Community Med Public Health 6: 1350.

88. Couto DV, Hans Filho G, Medeiros MZ, Vicari CFS, Barbosa AB, Takita LC, 2014. American tegumentary leishmaniasis: a case of therapeutic challenge. An Bras Dermatol 89: 974-976.

89. Herrera G, Hernández C, Ayala MS, Flórez C, Teherán AA, Ramírez JD, 2017. Evaluation of a multilocus sequence typing (MLST) scheme for Leishmania Niannia) braziliensis and Leishmania (Viannia) panamensis in Colombia. Parasit Vectors 10: 236.

90. Silva SC, Guimarães LH, Silva JA, Magalhães V, Medina L, Queiroz A, Machado PRL, Schriefer A, 2018. Molecular epidemiology and in vitro evidence suggest that Leishmania braziliensis strain helps determine antimony response among American tegumentary leishmaniasis patients. Acta Trop 178: 34-39. 
91. Ceccato $P$, Ramirez B, Manyangadze T, Gwakisa $P$, Thomson $M C, 2018$. Data and tools to integrate climate and environmental information into public health. Infect Dis Poverty 7: 126.

92. Salah I, Abbasi I, Warburg A, Davidovitch N, Kotler B, 2020. Ecology of leishmaniasis in an urbanized landscape: relationship of sand fly densities, and Leishmania tropica infection rates with reservoir host colonies. Acta Trop 204: 105332.

93. Hotez PJ, 2018. The rise of leishmaniasis in the twenty-first century. Trans $R$ Soc Trop Med Hyg 112: 421-422.

94. Purse BV, Masante D, Golding N, Pigott D, Day JC, IbañezBernal S, Kolb M, Jones L, 2017. How will climate change pathways and mitigation options alter incidence of vectorborne diseases? A framework for leishmaniasis in South and Meso-America. PLoS One 12: e0183583.

95. Afrin F, Khan I, Hemeg HA, 2019. Leishmania-host interactions: an epigenetic paradigm. Front Immunol 10: 492.

96. Berry I, Berrang-Ford L, 2016. Leishmaniasis, conflict, and political terror: a spatio-temporal analysis. Soc Sci Med 167: 140-149.
97. Murshed SM, 2002. Conflict, civil war and underdevelopment: an introduction. J Peace Res 39: 387-393.

98. Rehman K, Walochnik J, Mischlinger J, Alassil B, Allan R, Ramharter M, 2018. Leishmaniasis in northern Syria during civil war. Emerg Infect Dis 24: 1973-1981.

99. da Rocha ICM, dos Santos LHM, Coura-Vital W, da Cunha GMR, Magalhães F do C, da Silva TAM, Morais MHF, Oliveira E, Reis IA, Carneiro M, 2018. Effectiveness of the Brazilian Visceral Leishmaniasis Surveillance and Control Programme in reducing the prevalence and incidence of Leishmania infantum infection. Parasit Vectors 11: 586. Available at: https://pubmed. ncbi.nIm.nih.gov/30419944/.

100. Klohe K, Amuasi J, Kaducu JM, Haavardsson I, Bogatyreva E, Onarheim KH, Harrison W, Kristensen F, Prazeres da Costa C, Winkler AS, 2019. The 2017 Oslo conference report on neglected tropical diseases and emerging/re-emerging infectious diseases: focus on populations underserved. Infect Dis Poverty 8: 40. 